Enric Samsó MD PhD, Jordi Vallés MD, Olga Pol PhD, Lluis Gallart MD PhD, Margarita M. Puig MD PhD

\title{
Comparative assess- ment of the anaesthetic and analgesic effects of intramuscular and epidural clonidine in humans
}

Purpose: The aim of the study was to assess and compare in analogous controlled experimental conditions, the anaesthetic sparing and analgesic effects of the same dose of clonidine administered by the intramuscular (im) and epidural (ep) routes.

Methods: We used a randomized, double blind and placebo controlled protocol. Sixty patients undergoing abdominal hysterectomy were distributed into three groups who, $30 \mathrm{~min}$ before surgical incision, received: $300 \mu \mathrm{g}$ ep clonidine plus im saline; ep saline plus $300 \mu \mathrm{g}$ im clonidine; or ep and im saline (ss). General anaesthesia was maintained with $60 \% \mathrm{~N}_{2} \mathrm{O}$ in $\mathrm{O}_{2}$, and isoflurane administered at concentrations to maintain mean arterial pressure (MAP) and heart rate $(H R)$ within $20 \%$ of basal values. Isoflurane requirements (mass spectrometry), cardiovascular variables (MAP, HR), and plasma concentrations of glucose, cortisol and prolactin were evaluated at criti-

Key words

ANAESTHETICS INHALATIONAL: isoflurane;

ANAESTHETIC TECHNIQUES: inhalational;

ANALGESIA: postoperative;

SYMPATHETIC NERVOUS SYSTEM: pharmacology, clonidine.

From the Department of Anaesthesiology, Hospital Universitario del Mar, Anaesthesiology Research Unit, IMIM. Paseo Marítimo 25, 08003 Barcelona, Spain.

Address correspondence to: Dr. Margarita M. Puig,

Department of Anaesthesiology, Hospital Universitario del

Mar, Paseo Marítimo 25, 08003 Barcelona, Spain.

Preliminary results presented at the European Society of Anaesthesiologists Annual Congress, Brussels, February, 1994.

Partially supported by a Grant from the Fondo de Investigaciones Sanitarias, Ministerio de Sanidad y Consumo, Madrid, Spain (94/1380)

Accepted for publication July 21, 1996. cal time points. In the recovery room (RR), sedation (Ramsay) and pain intensity (VAS) were estimated at the time of analge. sia request (TAR).

Results: Intramuscular and ep clonidine decreased isoflurane requirements similarly by about $85 \%(P<0.001)$. Patients in the ep group had lower MAP $(P<0.03)$ and $H R(P<0.001)$ than in the im group, but im and ep clonidine similarly blunted the plasma prolactin increase induced by intubation. In $R R$, ep but not im clonidine $(P<0.01)$ induced postoperative analge. sia demonstrated by a prolonged TAR $80.8 \pm 7.3$ (ep) $35.9 \pm$ 3.2 ( im) and $44.5 \pm 5.1$ (ss) min and a lower VAS $(P<0.05)$.

Conclusions: Epidural and intramuscular clonidine decreased isoflurane requirements similarly, but only the epidural route provided postoperative analgesia, suggesting a spinal site for the analgesic action.

Objectif: Évaluer et comparer dans des conditions expérimentales identiques, l'effet d'épargne anesthésique et analgésique d'une même dose de clonidine administrée par la voie intramusculaire (IM) ou épidurale (Ép).

Méthodes: Un protcole aléatoire, en double aveugle et contrôlé avec placebo était utilisé. Soixante patientes programmées pour uné hystérectomie abdominale étaient réparties en trois groupes qui, 30 min avant l'incision de la peau, recevaient: de la clonodine $300 \mu g$ ép et du sol. phys. im; du sol. phys ép et de la clonidine $300 \mu \mathrm{g}$ im; ou du sol. phys. ép et im (ss). L'anesthésie générale était maintenue avec $\mathrm{N}_{2} \mathrm{O} 60 \%$ dans $\mathrm{O}_{2}$ et des concentrations d'isoflurane suffisantes pour maintenir la pression artérielle moyenne (PAM) et la fréquence cardiaque (FC) à $20 \%$ des valeurs initiales. Les besoins en isoflurane (spectrométrie de masse), les paramètres cardiaques (PAM, FC) et la glycémie, la cortisolémie et la prolactinémie étaient évalués au moment des intervalles cruciaux. En salle de réveil, la sédation (Ramsay) et l'intensité de la douleur (EVA) étaient évalués par la durée de l'intervalle précédant la dẹmande d'analgésique (IPDA).

Résultats: La clonidine IM et Ép a diminué également les besoins en isoflurane par environ $85 \%(P<0,001)$. Les 
patientes du groupe ép avaient des PAM plus basses $(P<$ $0,03)$ et des $F C$ plus lentes $(P<0,001)$ que celles du groupe im, mais la clonidine im et ép a diminué également l'augmentation de la concentration plasmatique de prolactine provoquée par l'intubation. À la salle de réveil, la clonidine ép contrairement à la clonidine im $(P<0,01)$ a induit l'analgésie postopératoire comme le démontrait un IPDA prolongé à 80,8 $\pm 7,3$ (ép), 35,9 $\pm 3,2$ (im) et 44,5 $\pm 5,1$ (ss) min et une EVA moins élevée.

Conclusion: La clonidine épidurale et intramusculaire diminue les besoins en isoflurane également, mais seule la voie épidurale procure une analgésie postopératoire, ce qui suggère un site d'action rachidien pour l'analgésie.

Several reports have shown that clonidine decreases intravenous $^{1-3}$ and inhalational ${ }^{4,5}$ anaesthetic requirements when administered in the preoperative period. In these and other studies, clonidine was given by different routes and modes of administration: po, im, ep or $i v$, in bolus or infusion, as premedication and/or during surgery. By decreasing the requirements of general anaesthetics and providing cardiovascular stability, clonidine has been shown to be an adjuvant to general anaesthesia and to decrease pharmacy cost during surgery. ${ }^{6}$ However, some confusion still exists regarding the optimal route of administration of clonidine when used in the immediate preoperative period. In the present study we have used the $i m$ and $e p$ routes of administration based on the work of Bonnet et al. ${ }^{7}$ who demonstrated, in the postoperative period, a comparable analgesic effect and plasma pharmacokinetic disposition of clonidine when administered by either route. However, due to higher and long lasting concentrations of the drug in the CSF after epidural administration, ${ }^{8.9}$ we hypothesized different anaesthetic/analgesic effects, possibly related to different sites of action after $e p$ and $i m$ administration. Clonidine administered by either route (im or $e p$ ), diffuses to the systemic circulation ${ }^{8,9}$ and binds to supraspinal sites which mediate sedation, $\mathrm{CV}$ depression and, supposedly, supraspinal analgesia. In addition, $e p$ clonidine binds to spinal alpha $\mathrm{a}_{2}$ adrenergic receptors and induces effective segmental analgesia ${ }^{8.9}$ and, probably, a certain degree of sympathetic blockade.

The dose of clonidine was selected based on the doseresponse relationship reported by Eisenach et al. ${ }^{10}$ who showed an $\mathrm{ED}_{50}$ for the analgesic effect of epidural clonidine of approximately $300 \mu \mathrm{g}$. In addition, other investigators have reported poor analgesia with $150 \mu \mathrm{g}$ epidural clonidine ${ }^{11,12}$ and almost complete analgesia with doses ranging from $400-600 \mu \mathrm{g} .{ }^{13}$ No reports could be found regarding a dose-relationship for the analgesic effects of clonidine after im administration.
The aim of the present investigation was to assess and compare the anaesthetic and analgesic effects of the same dose $(300 \mu \mathrm{g})$ of $\mathrm{im}$ and $e p$ clonidine during general anaesthesia. We evaluated, in the same controlled experimental conditions: (a) the anaesthetic sparing effects of clonidine, (b) the response to surgical stress by haemodynamic and neuroendocrine markers (cortisol, glucose and prolactin) and (c) postoperative analgesia. Our experimental protocol differs from other studies in that the same dose of clonidine was administered by two routes ( $\mathrm{im}, \mathrm{ep}$ ) to different groups of patients, in whom the above variables (anaesthetic sparing, haemodynamic, analgesic) were evaluated simultaneously in controlled experimental conditions. The results were compared with those from a placebo group to obtain clinically useful data for the use of clonidine during general anaesthesia.

\section{Methods}

The study was approved by the Ethics Committee of the Hospital, and informed consent was obtained from all patients. Sixty female ASA I-II patients (age 34-57 yr) scheduled for total abdominal hysterectomy (TAH) entered the study. The sample size was calculated using a power of 0.80 and an alpha risk of 0.05 in a two sided test with an expected difference of $40 \%$. On the night before surgery, patients were visited by an attending anaesthetist and randomly assigned to one of three treatment groups ( $n=20$ each group). Patients were premedicated with $10 \mathrm{mg}$ diazepam (po) given the night before surgery and another $10 \mathrm{mg} \mathrm{sl}$ one hour before the procedure.

On arrival in the operating room, ECG, automated non-invasive blood pressure and pulse oximetry were monitored. An intravenous catheter was placed in the non-dominant arm and $500 \mathrm{ml}$ Ringer's lactate were administered over $30 \mathrm{~min}$; the same solution was used for maintenance during anaesthesia. Intraoperatively, fluids were administered according to insensible loses, surgical bleeding and diuresis. With the patient in the lateral decubitus an epidural catheter was placed through an $18 \mathrm{G}$ Tuohy needle at $\mathrm{L}_{2-3}$. At this time, $3 \mathrm{ml}$ lidocaine $1.5 \%$ with epinephrine were administered through the catheter to rule out intravascular or subarachnoid injection. Five minutes later, all patients received, in a double blind manner, an im $(2 \mathrm{ml})$ plus ep injection $(12 \mathrm{ml})$ of the scheduled treatment according to the experimental design shown in Table $I$.

Patients in Group I received $300 \mu \mathrm{g}$ clonidine $e p$ and saline $\mathrm{im}$; Group II, had $300 \mu \mathrm{g}$ clonidine $i m$ and saline $e p$, and Group III saline, $e p$ and $i m$. The investigator who administered anaesthesia was blinded to the $e p$ and im solutions dispensed. Patients were then placed 
TABLE I Experimental treatment groups

\begin{tabular}{lll}
\hline Group & Epidural & Intramuscular \\
\hline I & Clonidine & Saline \\
II & Saline & Clonidine \\
III & Saline & Saline \\
\hline
\end{tabular}

Clonidine $(300 \mu \mathrm{g})$ was administered in $2(\mathrm{im})$ or $12 \mathrm{ml}(e p)$ of saline. Group III received the same volumes of saline.

supine, pre-oxygenated with $100 \% \quad \mathrm{O}_{2}$, and general anaesthesia was induced with $3 \mathrm{mg}$ midazolam, 0.01 $\mathrm{mg} \cdot \mathrm{kg}^{-1}$ atropine and thiopentone at hypnotic doses, $4-5 \mathrm{mg} \cdot \mathrm{kg}^{-1}$, iv. Vecuronium, $0.1 \mathrm{mg} \cdot \mathrm{kg}^{-1}$, iv was used to facilitate tracheal intubation and patients than received isoflurane in $\mathrm{O}_{2} / \mathrm{N}_{2} \mathrm{O}(40 / 60 \%)$ at a fixed inspired concentration of $1 \%$ for $15 \mathrm{~min}$ (fresh gas flow $0.1 \mathrm{~L} \cdot \mathrm{kg}^{-1}$ via semi-closed circuit), to provide sufficient analgesia for surgical incision in all experimental groups. Subsequently, isoflurane was administered (by increments or reductions of $0.2 \%$ ) at concentrations that the (blinded) anaesthetist estimated necessary to maintain cardiovascular variables mean arterial pressure (MAP) and heart rate (HR) within $20 \%$ of preoperative values.

According to pharmacokinetic behaviour of im and $e p$ clonidine, endotracheal intubation (ETT) was performed approximately $15 \mathrm{~min}$ after drug administration, coinciding with peak plasma concentrations. ${ }^{9}$ Surgical incision was deferred until $30 \mathrm{~min}$ from administration of the $e p$ or im medication to ensure adequate CSF concentrations of clonidine and thus its full analgesic effect. ${ }^{9}$ Muscle relaxation was evaluated using a peripheral nerve stimulator, and maintained with vecuronium. All patients had an arterial line placed in the radial artery of the non-dominant hand for continuous monitoring of blood pressure and blood sample collection. On the completion of surgery, neuromuscular blockade was reversed with neostigmine and atropine and the tracheas were extubated in the operating room.

During anaesthesia, respiratory gases $\left(\mathrm{O}_{2}, \mathrm{CO}_{2}, \mathrm{~N}_{2} \mathrm{O}\right.$, isoflurane, and $\mathrm{N}_{2}$ ) were monitored at intervals of 12-90 sec by mass spectrometry. Values of the individual expired concentrations of isoflurane were stored in sequential manner on a computer disk and used later for calculation of the isoflurane requirements. Results are expressed as mean \% expired concentrations (MEC, weighted mean of overall concentrations obtained during anaesthesia) and as the averaged area under the curve (AUC, \% isoflurane over time) in the different experimental groups. Our results have been calculated: (a) as the \% mean expired concentration (MEC) of isoflurane required for the total duration of anaesthesia
(MEC-T); (b) as the MEC administered prior to surgical incision (MEC-1) and (c) as the MEC required from incision until the completion of surgery (MEC-2). Results are also expressed as the AUC for each time period (AUC-T, AUC-1, AUC-2).

Depth of anaesthesia was determined by strict evaluation of cardiovascular variables (MAP, HR) and isoflurane requirements were established on the basis of hypertension and tachycardia. Although MAP and HR were continuously registered during surgery, for the purpose of the study they were recorded at the following times: preoperatively (PRE-OP) the night before surgery; prior (ETT-PRE) and immediately after tracheal intubation (ETT-POST); pre- and post-surgical incision (SI-PRE and SI-POST) and on arrival to recovery room (RR). At the same times, blood samples $(6 \mathrm{ml})$ for determination of plasma glucose, cortisol and prolactin were collected, centrifuged at $4^{\circ} \mathrm{C}$, and the plasma frozen and stored at $-80^{\circ} \mathrm{C}$ until the day of the assay.

In the recovery room (RR), ECG, MAP, HR and \% $\mathrm{O}_{2}$ Saturation were continuously monitored. A simple visual analogue scale (VAS) graded 1-10 was used to evaluate the intensity of pain, while the degree of sedation was established by the Ramsay scale which includes $1-6$ points. ${ }^{14}$ Both variables were measured at the time of analgesia request (TAR) considered as the period elapsed between extubation and request of analgesia, and carefully charted by the nurse in charge. At this time $75 \mathrm{mg}$ diclofenac im were administered as analgesic.

All patients were visited the following day by an attending anaesthetist, and questioned regarding intraoperative recall and/or other events related to the administration of anaesthesia.

Plasma glucose concentration was measured on a Technikon auto-analyzer II system using the glucoseoxidase method. Plasma cortisol and prolactin were determined by radioimmunoassay; the assays had lower sensitivities of $0.2 \mu \mathrm{g} \cdot \mathrm{dl}^{-1}$ and $0.14 \mathrm{ng} \cdot \mathrm{ml}^{-1}$ respectively.

Statistical analysis was carried out with a microcomputer program (SPSS/PC+, version 4.0, Microsoft Corporation). Results are expressed as mean \pm SEM. Comparison of demographic data, PRE-OP haemodynamic variables and duration of surgery were performed by one way ANOVA. Comparison of isoflurane requirements among the three groups was carried out by one way ANOVA followed by Newman-Keuls test; when groups did not show homogeneity of variances, a nonparametrical ANOVA (Kruskal-Wallis) was performed followed by a Mann-Whitney U-test.

Statistical differences for interval data (MAP, HR, hormonal plasma concentrations) among groups were 
established by analysis of variance for repeated measures (MANOVA); intragroup evaluation was performed by one-way analysis of variance followed by a post-hoc Students Newman-Keuls test. A $P<0.05$ was considered statistically significant.

\section{Results}

\section{Isoflurane requirements}

The groups were comparable regarding demographic data, baseline haemodynamic variables and duration of surgery (Table II).

Patients who received $300 \mu \mathrm{g}$ clonidine, either by the epidural (Group I) or by intramuscular (Group II) routes, required lower concentrations of isoflurane than did the saline group (III) for the total duration of surgery (T) and from surgical incision to the end of surgery (Kruskal-Wallis, $P<0.001$ ). Table III presents mean isoflurane requirements and $\mathrm{AUC}$, in the three groups of treatment. Figure 1 shows mean \% expired isoflurane concentrations over mean duration of surgery, in patients who received $i m$ clonidine (Group II) and saline (Group III). Patients in Group I (ep clonidine) are not represented in the figure since the data overlap with those of Group II. In the figure, the rapid decline in isoflurane concentration after $15 \mathrm{~min}$ in the im clonidine group (dark area) reflects the fact that, after surgical incision, these patients did not need additional isoflurane to maintain MAP and HR in the $20 \%$ range of PRE-OP values. Administration of $300 \mu \mathrm{g}$ im or $e p$ clonidine, reduced isoflurane requirements by approximately $85 \%$ during surgical anaesthesia (time 2 ). Since no differences were observed between Groups I and II, the results also demonstrate that the sparing effect of isoflurane is independent of the route $(e p$ or $i m)$ of administration of clonidine.

\section{Haemodynamic evaluation}

The MAP and HR were recorded at five minute intervals throughout surgery and evaluated at crucial time points. For blood pressure, MANOVA shows an effect of treatment $(P<0.009)$, time $(P<0.001)$ as well as for the interaction $(P<0.026)$, related to a lower MAP observed in the $e p$-CL group at all times except ETTPOST and RR. In addition, MAP in $e p$-CL was significantly lower than IM-CL before tracheal intubation (ETT-PRE) and after surgical incision (SI-POST) (Figure 2). None of the patients required additional atropine for bradycardia, and one patient in the epidural group received intravenous ephedrine $(5 \mathrm{mg}$ bolus, twice) for hypotension. No significant differences were observed among groups regarding blood loss, fluid replacement or urinary output; in addition, none of the
TABLE II Demosgraphic characteristics

\begin{tabular}{lrcr}
\hline Group & $I$-epidural & II-intramuscular & III-saline \\
\hline Age - yr & $44.0 \pm 1.3$ & $45.7 \pm 2.0$ & $44.9 \pm 2.3$ \\
Weight - kg & $61.9 \pm 2.2$ & $61.2 \pm 1.8$ & $65.0 \pm 2.1$ \\
Height - cm & $159.4 \pm 1.6$ & $158.3 \pm 0.9$ & $157.2 \pm 1.8$ \\
MAP - mmHg & $91.5 \pm 2.2$ & $100.7 \pm 2.9$ & $93.5 \pm 3.1$ \\
HR - bpm & $81.1 \pm 2.3$ & $80.0 \pm 1.8$ & $78.6 \pm 3.1$ \\
Surgery - min & $113.4 \pm 5.0$ & $102.2 \pm 5.8$ & $117.9 \pm 5.9$ \\
\hline
\end{tabular}

Baseline values (mean \pm SEM) for MAP and HR were obtained the night before surgery.

TABLE III Comparison of isoflurane requirements

\begin{tabular}{cccc}
\hline Group & 1 -epidural & $I I$-intramuscular & $I I$-saline \\
\hline MEC-T & $0.15 \pm 0.01 a$ & $0.16 \pm 0.01 a$ & $0.51 \pm 0.03 b$ \\
AUC-T & $15.9 \pm 1.5 a$ & $15.8 \pm 1.1 a$ & $61.9 \pm 5.9 b$ \\
MEC-1 & $0.44 \pm 0.03 a$ & $0.57 \pm 0.03 a$ & $0.53 \pm 0.04 a$ \\
AUC-1 & $7.8 \pm 0.5 a$ & $8.3 \pm 0.5 a$ & $8.0 \pm 0.6 a$ \\
MEC-2 & $0.08 \pm 0.01 a$ & $0.09 \pm 0.02 a$ & $0.5 \pm 0.04 b$ \\
AUC-2 & $8.1 \pm 0.9 a$ & $7.5 \pm 1.0 a$ & $53.8 \pm 6.0 b$ \\
\hline
\end{tabular}

$\mathrm{MEC}=$ mean exhaled concentration of isoflurane $(\%) ; \mathrm{AUC}=$ area under the curve of $\%$ isoflurane over time. $T=$ total duration of surgery. $1=$ time from induction to surgical incision. $2=$ time from incision to completion of surgery. $n=20$ patients per group. For each time (T, 1, 2) and variable (MEC, AUC), different letters $(a, b)$ indicate $P<0.001$ (Kruskal-Wallis, followed by U-Mann Whitney), while the same letter $(a, a)$ indicates no significant differences.

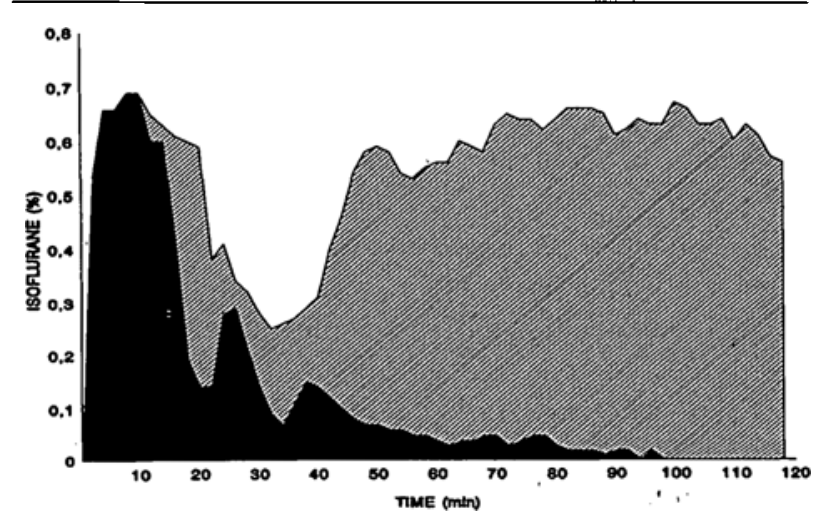

FIGURE 1 Mean expired isoflurane concentrations (\%) over time of surgery, in patients receiving $300 \mu \mathrm{g}$ im clonidine (dark area) or saline (striped area). $n=20$ each group.

patients required transfusion of blood products. Heart rate varied over time $(P<0.001)$, although no differences were observed due to treatment (MANOVA); however, their interaction was statistically significant $(P$ $<0.001$ ) related to a lower HR observed in patients receiving EP-CL at SI-PRE and SI-POST (Figure 2). Thus, the epidural administration of clonidine produces 


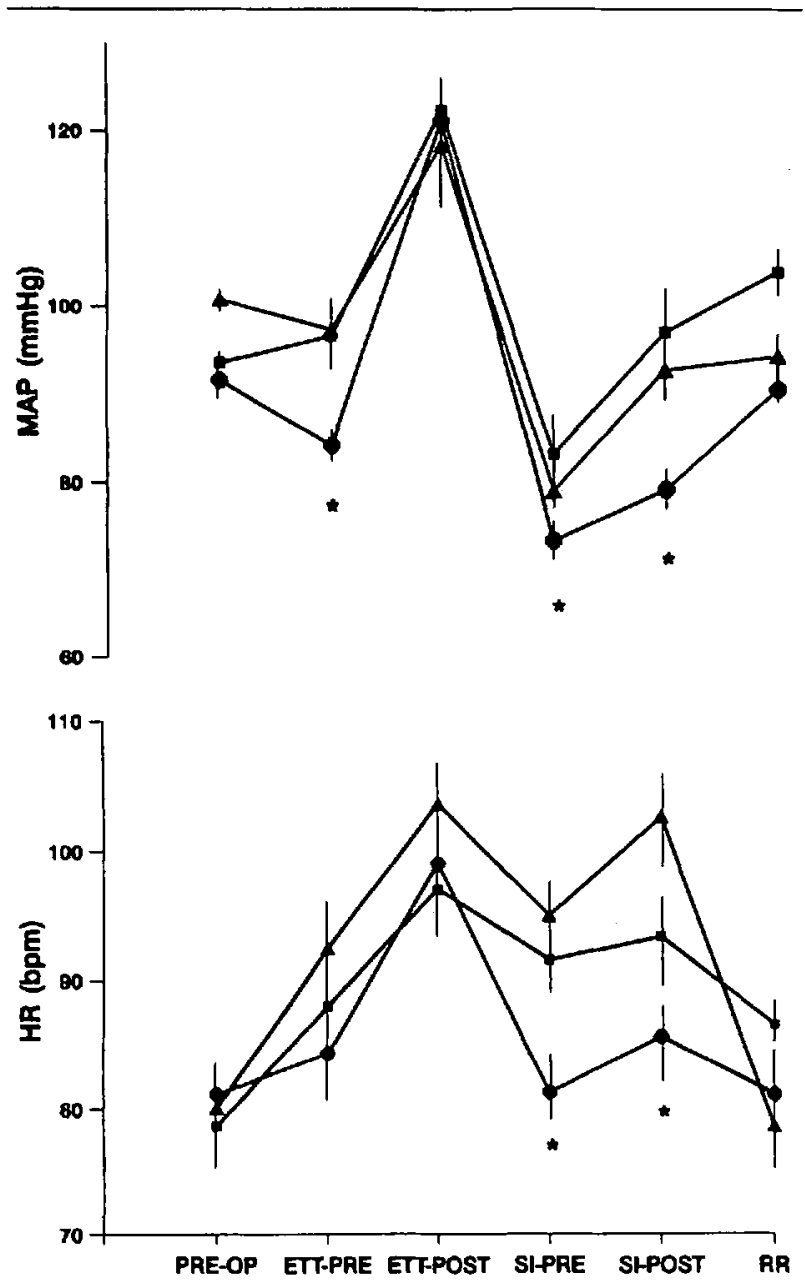

FIGURE 2 MAP (upper panel) and HR (lower) in patients receiving ep $\mathrm{CL}$, im $\mathrm{CL}$ or saline. PRE-OP, baseline values; E'TT-PRE and POST, values obtained before and five minutes after tracheal intubation; SI-PRE and POST, the same regarding surgical incision; RR on arrival to the recovery room. Circles, ep CL; triangles im $\mathrm{CL}$ and squares, SS. $* P<0.04$ (Student's Neuwman Keuls), when $e p C L$ is compared with other groups.

lower MAP and HR than the same dose of the drug administered $\mathrm{im}$.

\section{Evaluation of the stress response}

Preoperative plasma concentrations of glucose, cortisol and prolactin the night before surgery were within normal limits. In the operating room and in the RR, for glucose and cortisol, there was an effect of time $(P<0.001)$ but no differences due to treatment or their interaction (Table IV). Similarly, prolactin plasma concentrations (Figure 3) showed an effect of time, but no differences related to treatment; however, their interaction demonstrated an effect $(P<0.02)$ due to a higher prolactin
TABLE IV Significance levels for plasma concentrations of glucose, cortisol and prolactin (multivariate analysis of variance, MANOVA). For each substance, the effects of treatment ( $e p \mathrm{CL}$, im CL or SS), time (PRE-OP, ETT-PRE, ETT-POST, SI-PRE, SI-POST, $\mathrm{RR}$ ) and their interaction have been evaluated. All variables show an effect of time, and prolactin also exhibits an interaction effect

\begin{tabular}{llll}
\hline Variable & Treatment effect & Time effect & Interaction \\
\hline Glucose & NS & $P<0.001$ & NS \\
Cortisol & NS & $P<0.001$ & NS \\
Prolactin & NS & $P<0.001$ & $P<0.02$ \\
\hline
\end{tabular}

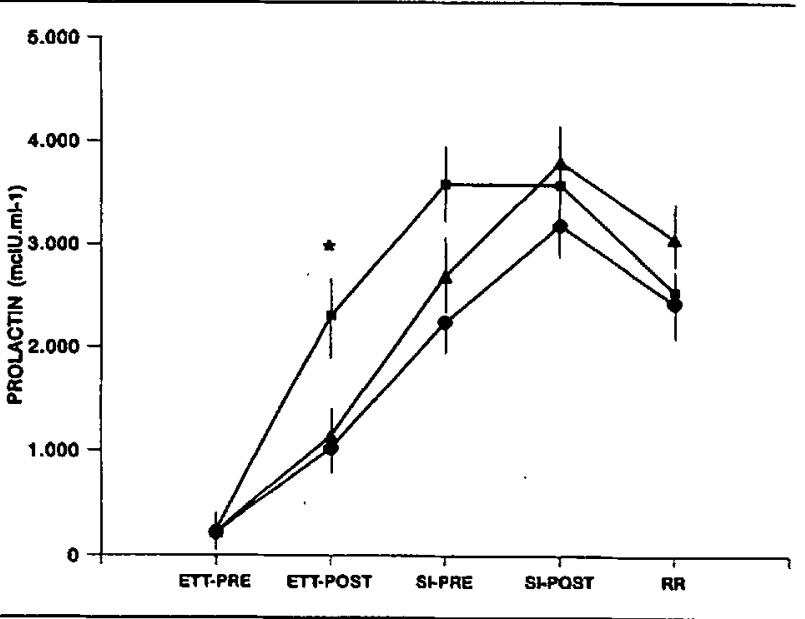

FIGURE 3 Plasma concentrations of prolactin $\left(\mu \mathrm{IU} \cdot \mathrm{ml}^{-1}\right)$ in patients receiving e $p \mathrm{CL}$, im $\mathrm{CL}$ or saline. ETT-PRE and POST, values obtained before and five minutes after tracheal intubation; SI-PRE and POST, the same regarding surgical incision; RR on arrival to the recovery room. Circles, $e p \mathrm{CL}$; triangles $i m \mathrm{CL}$ and squares, $\mathrm{SS} .{ }^{*} P<$ 0.02 (Kruskal-Wallis) when SS is compared with other groups.

concentration in the SS group immediately after tracheal intubation (ETT-POST).

\section{Postoperative evaluation}

Patients in the ep clonidine group had a prolonged TAR and a lower VAS than did the other two groups (ANOVA, $P<0.001$ ) (Table V). No differences in $\% \mathrm{O}_{2}$ saturation or degree of sedation were observed. On the postoperative visit none of the patients had recall of intraoperative events and degree of satisfaction was consistently acceptable.

\section{Discussion}

Previous studies have demonstrated that the administration of clonidine by different routes, decreases the requirements of intravenous ${ }^{1-3}$ and inhalational anaesthetics ${ }^{4,5}$ and produces postoperative analgesia. ${ }^{2,3}$ In our study we investigated the anaesthetic sparing, and analgesic effects of the same dose of clonidine administered by the im or $e p$ routes. We speculated that the effects of 
TABLE V Postoperative evaluation (mean \pm SEM or range)

\begin{tabular}{lccc}
\hline Group & 1 -epidural & II-intramuscular & III-saline \\
\hline TAR-min & $80.8 \pm 7.3 \dagger$ & $35.9 \pm 3.2$ & $44.5 \pm 5.1$ \\
VAS-1-10 & $3.1 \pm 0.4^{*}$ & $6.6 \pm 0.3$ & $6.3 \pm 0.3$ \\
O2 sat - \% & $97.0 \pm 0.3$ & $99.0 \pm 0.6$ & $98.3 \pm 0.4$ \\
Sedation-1-6 & $1.9 \pm 0.1$ & $1.8 \pm 0.1$ & $2.0 \pm 0.0$ \\
& $(1-3)$ & $(1-3)$ & $(1-4)$ \\
\hline
\end{tabular}

TAR = time of analgesia request; VAS = scores and degree of sedation evaluated at TAR. ANOVA for each parameter, followed by U-Mann-Whitney (TAR) or Neumann-Keuls.

$* P<0.05, \dagger P<0.01$ compared with the other groups.

clonidine would be better assessed and compared if they were evaluated in identical experimental controlled conditions. In addition, we wanted to explore if clonidine could be used as an alternative to local anaesthetics (LA) during combined epidural/general anaesthesia. Our results demonstrate that the administration of $300 \mu \mathrm{g}$ clonidine by the $e p$ or im routes, similarly decrease isoflurane requirements during $\mathrm{TAH}$, but only ep clonidine induced postoperative analgesia. The results also suggest that $300 \mu \mathrm{g} e p$ clonidine could be used during epidural/general anaesthesia, although a comparison of clonidine with LA was not attempted in the present investigation.

Our patients received atropine during induction of anaesthesia, and did not show bradycardia throughout the study. Interestingly, patients treated with ep clonidine had lower MAP than those in the other groups, indicating that this effect may be partially related to the spinal action of the drug. The present results confirm the findings reported by other investigators regarding $\mathrm{CV}$ stability and the sparing effect of general anaesthetics. ${ }^{1-5}$ However, the administration of a single dose of clonidine (im or $e p$ ), and the precise evaluation of exhaled isoflurane concentrations by mass spectrometry permitted a more precise evaluation of the sparing effects of inhalational anaesthetics, which is approximately $85 \%$ after $300 \mu \mathrm{g}$ of $e p$ or im clonidine.

We compared the intraoperative requirements of isoflurane in patients treated with im or ep clonidine, with those of a control group receiving saline by the im and $e p$ routes. In all patients isoflurane requirements were established on the basis of changes in MAP and HR over baseline values, which is the standard method used in the operating room to assess depth of anaesthesia; unfortunately no other methods to measure depth of anaesthesia are available in our institution. However, since clonidine reduces sympathetic outflow, ${ }^{15,16}$ evaluation of anaesthetic requirements based on the sympathetic response to surgical stimulation (hypertension and tachycardia), could be considered inadequate, and pa- tients receiving clonidine might have been inadequately anaesthetized. The inclusion of a control group in a double blind protocol, the fact that our patients had no recall of intraoperative events, and the similar changes observed in plasma concentrations of stress hormones in all groups suggests that the depth of anaesthesia was analogous and acceptable in all experimental conditions.

In this study, the response to stress was estimated by the measurement of plasma concentrations of different markers evaluated at critical time-points. Variations in plasma concentrations of different hormones including catecholamines, have been used as stress markers during surgery. ${ }^{17,18}$ However, different studies show that clonidine inhibits catecholamine release, ${ }^{19,20}$ interferes with cortisol turnover/biosynthesis, ${ }^{21,22}$ produces hyperglycaemia $^{23,24}$ and decreases prolactin secretion; ${ }^{25}$ but these changes do not seem to have clinical importance in humans. ${ }^{26}$ Based on the hormonal effects of clonidine, the evaluation of the stress response by any of the above markers, could be imprecise. Thus, we evaluated (simultaneously) the response to surgical stress by changes in plasma concentrations of glucose, cortisol and prolactin. The last has been claimed to be a very sensitive stress marker ${ }^{27}$ during surgery. We did not observe an effect of treatment on glucose and cortisol concentrations, suggesting a lower sensitivity of these substances as stress markers compared with prolactin. In our patients, plasma concentrations increased over time in a similar manner for all markers, reflecting a comparable degree of surgical stress in all groups. In addition, no differences were observed in cortisol and glucose concentrations in the clonidine groups compared with SS, indicating that the administration of a single bolus of $300 \mu \mathrm{g}$ clonidine does not alter glucose or cortisol plasma concentrations. An increase in prolactin plasma concentrations was observed after ETT in control (SS) patients, indicating that in our experimental conditions: (a) prolactin is a more sensitive marker of surgical stress; (b) $e p$ and $i m$ clonidine similarly prevent the stress response to intubation and (c) during surgery (after intubation of the trachea), all groups had a similar depth of anaesthesia. Plasma concentrations of the markers did not correlate with cardiovascular changes observed at critical time points (ETT-POST, SI-POST), but rather increased progressively over time, suggesting a delayed hormonal response to surgical stress.

The similarities between im and ep clonidine on isoflurane sparing effects and stress response to surgery could be related to their comparable plasma pharmacokinetic behaviour. However, the precise site/s of action of the drug after $e p$ and $i m$ administration may be different. Several studies show that, after systemic administration, the drug reaches supraspinal sites and induce 
sedation, CV depression and supposedly supraspinal analgesia; ${ }^{28-30}$ a small fraction of the drug would also reach the spinal cord by the bloodstream and induce spinal analgesia. Thus, the intraoperative analgesic/ anaesthetic effects of $\mathrm{im}$ clonidine could be considered to be mainly supraspinal. After EP administration, the drug selectively binds to alpha $a_{2}$ adrenergic receptors in the spinal cord, produces segmental analgesia ${ }^{9}$ and presumably a decrease in spinal sympathetic outflow, ${ }^{30}$ In addition, clonidine reaches supraspinal sites by systemic absorption and rostral diffusion in the CSF. ${ }^{31}$ Thus, after EP administration, the analgesic and $\mathrm{CV}$ effects of clonidine could be primarily related to binding of the drug to spinal sites. However, regardless of the precise site of (analgesic) action, our results demonstrate that isoflurane consumption can be similarly reduced by lumbar $e p$ or im clonidine during abdominal surgery.

In the $\mathrm{RR}$, time of analgesia request was prolonged approximately one hour in patients receiving ep (but not $\mathrm{im}$ ), clonidine. Taking into account the duration of surgery $(120 \mathrm{~min}$ ) the $e p$ administration of $300 \mu \mathrm{g}$ clonidine provided between over three hours of analgesia, confirming results obtained by others. ${ }^{7}$ The CSF pharmacokinetic behaviour of clonidine after $e p$ administration has been reported, ${ }^{8,9.12}$ and minimum analgesic CSF concentrations are about $76 \mathrm{ng} \cdot \mathrm{ml}^{-1} \cdot{ }^{9}$ Due to its lipophylicity, ep clonidine is easily absorbed into the CSF where it reaches peak analgesic concentrations approximately after $30 \mathrm{~min} .^{9,12}$ For this reason, we delayed surgical incision until $30 \mathrm{~min}$ had elapsed from the administration of the drug. Doses of ep clonidine in the range of $150-700 \mu \mathrm{g}$, show an absorption half-life and time to maximal concentration in CSF of 15-30 and 30-45 min respectively., ${ }^{8,12}$ These correspond to the onset and peak analgesic times for clonidine after lumbar epidural administration.

Although plasma pharmacokinetic behavour after im and $e p$ administration follows a similar pattern, CSF concentrations after systemic clonidine remain below analgesic levels. In our study, the evidence of postoperative analgesia in the $e p$ clonidine group, in the absence of sedation, confirms the spinal site of action of the drug and shows, that the analgesic and sedative effects of epidural clonidine do not follow a coinciding or parallel temporal pattern.

Patients in the ep group had lower VAS scores at the TAR, while no differences between im clonidine and saline were observed. One explanation may be the rapid elimination of isoflurane (in RR) in patients who did not receive intraoperative opioids, or a potential hyperalgesic effect of low concentrations of the anaesthetic, which would be masked by the analgesic effect of epidural clonidine. In another study from our group uti- lizing a similar experimental protocol, we showed that the administration of $300 \mu \mathrm{g} \mathrm{ep}$ clonidine, provided four hours of residual analgesia in patients anaesthetized with fentanyl as the primary anaesthetic, ${ }^{3}$ suggesting a synergistic interaction. Based on the duration of postoperative analgesia induced by ep clonidine after isoflurane anaesthesia, a similar type of interaction could be suggested.

The study showed that the administration of epidural clonidine has no advantages over the intramuscular route when evaluating the sparing effects of inhalational anaesthetics. Thus $e p$ or $i m$ clonidine provided similar cardiovascular stability during surgery, but neither protected the cardiovascular response to tracheal intubation. Lumbar epidural clonidine (but not $\mathrm{im}$ ) attenuated cardiovascular changes induced in response to skin incision, probably related to a segmental analgesic effect of the drug. By this route, clonidine also provided about one hour of effective postoperative analgesia. However, even if the epidural administration could be considered advantageous, the cost of the epidural kit, together with potential expense involved in the treatment of its possible side effects (i.e., dural puncture and delayed hospital discharge), could eliminate likely benefits associated with the routine administration of epidural clonidine during general anaesthesia.

\section{References}

1 Flacke JW, Bloor BC, Flacke WE, et al. Reduced narcotic requirement by clonidine with improved hemodynamic and adrenergic stability in patients undergoing coronary bypass surgery. Anesthesiology 1987; 67: 11-9.

2 De Kock M, Crochet B, Morimont $C$, Scholtes J-L. Intravenous or epidural clonidine for intra- and postoperative analgesia. Anesthesiology 1993; 79: 525-31.

3 Murga G, Samsó E, Valles J, Casanovas P, Puig MM. The effect of clonidine on intra-operative requirements of fentanyl during combined epidural/general anaesthesia. Anaesthesia 1994; 49: 999-1002.

4 Ghignone M, Calvillo O, Quintin L. Anesthesia and hypertension: the effect of clonidine on perioperative hemodynamics and isoflurane requirements. Anesthesiology 1987; 67: 3-10.

5 Ghignone $M$, Noe C, Calvillo O, Quintin L. Anesthesia for ophthalmic surgery in the elderly: the effects of clonidine on intraocular pressure, perioperative hemodynamics, and anesthetic requirement. Anesthesiology 1988; 68: 707-16.

6 Vallés J, Vilar X, Gallart Ll, Samsó E, Trillo L, Puig MM. Pharmacy savings in anaesthesia by preoperative administration of clonidine. Br J Anaesth 1995; 74: A292.

7 Bonnet F, Boico O, Rostaing S, Loriferne JF, Saada M. Clonidine-induced analgesia in postoperative patients: 
epidural versus intramuscular administration.

Anesthesiology 1990; 72: 423-7.

8 Glynn CJ, Jamous MA, Teddy PJ. Cerebrospinal fluid kinetics of epidural clonidine in man. Pain 1992; 49: 361-7.

9 Eisenach J, Detweiler D, Hood D. Hemodynamic and analgesic actions of epidurally administered clonidine. Anesthesiology 1993; 78: 277-87.

10 Eisenach JC, D'Angelo $R$, Taylor $C$, Hood DD. An isobolographic study of epidural clonidine and fentanyl after cesarean section. Anesth Analg 1994; 79: 285-90.

11 Bonnet $F$, Boici $O$, Rostaing $S$, et al. Postoperative analgesia with extradural clonidine. $\mathrm{Br} J$ Anaesth 1989; 63: 465-9.

12 Gordh $T J r$. Epidural clonidine for treatment of postoperative pain after thoracotomy. A double-blind placebo-controlled study. Acta Anesthesiol Scand 1989; 32: 702-9.

13 Eisenach JC, Lysak SZ, Viscomi CM. Epidural clonidine analgesia following surgery: phase I. Anesthesiology 1989; 71: 640-6.

14 Aitkenhead AR. Analgesia and sedation in intensive care. Br J Anaesth 1989; 63; 196-206.

15 Kooner JS, Birch R, Frankel HL, Peart WS, Mathias CJ. Hemodynamic and neurohormonal effects of clonidine in patients with preganglionic and postganglionic sympathetic lesions. Evidence for a central sympatholytic action. Circulation 1991; 84: 75-83.

16 Lowenthal DT, Matzek KM, MacGregor TR. Clinical pharmacokinetics of clonidine. Clin Pharmacokinet 1988; 14: 287-310.

17 Miralles F, Olaso MJ, Fuentes T, Lopez F, Laorden $M L$, Puig MM. Presurgical stress and plasma endorphin levels . (Letter). Anesthesiology 1983; 59: 366-7.

18 Walsh J, Puig MM, Lovitz MA, Turndorf H. Premedication abolishes the increase in plasma beta-endorphin observed in the immediate preoperative period. Anesthesiology 1987; 66: 402-5.

19 Veith RC, Best JD, Halter JB. Dose-dependent suppression of norepinephrine appearance rate in plasma by clonidine in man. J Clin Endocrinol Metab 1984; 59: 151-5.

20 Conway EL, Brown MJ, Dollery CT. No evidence for involvement of endogenous opioid peptides in effects of clonidine on blood pressure, heart rate and plasma norepinephrine in anesthetized rats. J Pharmacol Exp Ther 1984; 229: 803-8.

21 Maze $M$, Virtanen $R$, Daunt D, Banks SJM, Stover EP, Feldman $D$. Effects of dexmedetomidine, a novel imidazole sedative-anesthetic agent, on adrenal steroidogenesis: in vivo and in vitro studies. Anesth Analg 1991; 73: 204-8.

22 Lanes A, Herrera A, Palacios A, Moncada G. Decreased secretion of cortisol and ACTH after oral clonidine administration in normal adults. Metabolism 1983; 32: 568-70.
23 Angel I, Langer SZ. Adrenergic-induced hyperglycemia in anaesthetized rats: involvement of peripheral $\alpha_{2}$-adrenoceptors. Eur J Pharmacol 1988; 154: 191-6.

24 Metz SA, Halter JB, Robertson RP. Induction of defective insulin secretion and impaired glucose tolerance by clonidine. Selective stimulation of metabolic alpha-adrenergic pathways. Diabetes 1978; 27: 554-62.

25 Borromeo V, Berrini A, Möller F, Secchi C. Inverse control of growth hormone and prolactin secretion in clonidine-stimulated dairy cattle. J Endocrinol 1995; 146:271-7.

26 Maze $M$, Tranquilli $W$. Alpha-2 adrenoceptor agonists: defining the role in clinical anesthesia. Anesthesiology 1991; 74:581-605.

27 Blunnie WP, Mcllroy PDA, Merrett JD, Dundee JW. Cardiovascular and biochemical evidence of stress during major surgery associated with different techniques of anaesthesia. Br J Anaesth 1983; 55: 611-8.

28 Bernard J-M, Hommeril J-L, Passuti N, Pinaud $M$. Postoperative analgesia by intravenous clonidine. Anesthesiology 1991; 75: 577-82.

29 De Kock M, Martin N, Scholtes JL. Central effects of epidural and intravenous clonidine in patients anesthetized with enflurane/nitrous oxide. Anesthesiology 1992; 77 : 457-62. '

30 Eisenach JC, Tong C. Site of hemodynamic effects of intrathecal $\alpha_{2}$-adrenergic agonists. Anesthesiology 1991; 74: 766-71.

31 Jarrot B, Conway EL, Maccarrone C, Lewis SJ. Clonidine: understanding its disposition, sitès and mechanism of action. Clin Exp Pharmacol Physiol 1987; 14: 471-9. 